\title{
PENGARUH CAMPURAN MINYAK PLASTIK LOW DENSITY POLYETHYLINE (LDPE) DENGAN VARIASI BAHAN BAKAR TERHADAP PERFORMA GAS BUANG
}

\author{
EFFECT OF MIXTURE OF PLASTIC OIL LOW DENSITY POLYETHYLENE (LDPE) WITH \\ VARIATION OF FUEL ON PERFORMANCE OF WASTE GAS
}

\section{Rahmat Hidayat ${ }^{1}$, Nely Ana Mufarida, S.T., M.T. ${ }^{2}$, Rohimatush Shofiyah, S.Si., M.Si. ${ }^{3}$}

${ }^{1}$ Mahasiswa, ${ }^{2}$ Dosen Pembimbing 1, ${ }^{3}$ Dosen Pembimbing 2, Program Studi Teknik Mesin, Fakultas Teknik, Universitas Muhammadiyah Jember E-mail : dayat.citul@gmail.com

\begin{abstract}
ABSTRAK
Penelitian ini bertujuan untuk mengetahui apakah minyak plastik dapat digunakan sebagai bahan bakar alternative dan juga mengetahui pengaruh campuran minyak plastik denagan premium, pertalite dan juga pertamax terhadap performa emisi gas buang. Penelitian ini untuk mengetahui kadar emisi gas buang $\mathrm{HC}$ dan $\mathrm{CO}$ dengan mengunakan gas analyzer. Hasil penelitian ini di ketahui premium yang di campurkan minyak plastik $10 \%$ mengalami penurunan sebesar $606 \mathrm{ppm}$ HC dan CO mengalami penurunan sebesar 1,24\%, untuk yang campuran 15\% mengalami penurunan $\mathrm{HC}$ sebesar $701 \mathrm{ppm}$ dan CO sebesar 1,3\% dari premium murni yang di uji. Denagan bahan bakar jenis pertalite denagn komposisi $10 \%$ minyak plastik gas HC mengalami penurunan sebesar $408 \mathrm{ppm}$ dan CO sebesar 0,97 $\%$, untuk komposisi $15 \%$ mengalami penurunan gas HC sebesar $915 \mathrm{ppm}$ dan gas CO mengalami penurunan sebesar 3,04\% dari pertalite murni yang di uji. Untuk bahan bakar pertamax yang di campur $10 \%$ minyak plastik gas $\mathrm{HC}$ menurun sebesar $139 \mathrm{ppm}$ untuk $\mathrm{CO}$ sebesar $0,33 \%$ dan campuran 15\% menurun sebesar 398 ppm pada gas HC 0,93\% pada gas CO dari pertamax yang di uji. Kata kunci : Plastik LDPE, Pirolisis, Campuran Bahan Bakar, Emisi Gas Buang.
\end{abstract}

\begin{abstract}
This research aims to determine whether plastic oil can be used as an alternative fuel and also to know the influence of plastic oil mixture denagan premium, pertalite and also pertamax to exhaust gas emission performance This research is to know the level of exhaust emission of HC and CO by using gas analyzer. The results of this research is known that the premium mixed with $10 \%$ plastic oil decreased by $606 \mathrm{ppm} \mathrm{HC}$ and CO decreased by 1.24\%, for which the 15\% mixture decreased HC by 701 ppm and CO by $1.3 \%$ from pure premium which was tested. Denagan fuel type pertalite with $10 \%$ composition of HC gas plastic oil decreased by 408 ppm and CO 0.97\%, for the composition of 15\% decreased HC gas by 915ppm and CO gas decreased by 3.04\% from pure in test. For the mixed pertamax fuel $10 \%$ of HC gas plastic oil decreased by 139 ppm for CO by $0.33 \%$ and the $15 \%$ mix decreased by 398 ppm in HC gas $0.93 \%$ in CO gas of pertamax under test.
\end{abstract}

Keywords: LDPE plastic, pyrolysis, fuel mixture, exhaust emissions

\section{PENDAHULUAN}

Cadangan bahan bakar fosil yang semakan menipis dan meningkatnya populasi manusia sangat kontradiktif dengan kebutuhan energi bagi kelangsungan hidup manusia beserta aktivitas ekonomi dan sosialnya. Sejak lima tahun terakhir, Indonesia mengalami penurunan produksi minyak nasional akibat menurunnya cadangan minyak pada sumur-sumur produksi secara alamiah, padahal dengan pertambahan jumlah penduduk, meningkat pula kebutuhan akan sarana transportasi dan aktivitas industri. Hal ini berakibat pada peningkatan kebutuhan dan konsumsi bahan bakar minyak (BBM) yang merupakan sumber daya alam yang tidak dapat diperbaharui. Pemerintah masih mengimpor sebagian BBM untuk memenuhi kebutuhan dalam negeri.

Beberapa upaya yang telah dilakukan oleh pemerintah untuk mengatasi krisis energi diantaranya adalah dengan mengembangkan bahan bakar alternatif, yang berasal dari sumberdaya energi terbarukan, batubara, hidrogen, nuklir dan lain-lain. 
Namun, penelitian dan pengembangan energi baru yang selama ini dilakukan hanya berfokus pada pengembangan sumber dari bahan nabati, tambang dan nuklir. Padahal masih terdapat banyak sumber lain yang berpotensi cukup besar sebagai sumber energi baru. Salah satunya adalah limbah atau sampah.

Menurut (Nishino, et.al. 2003) jumlah limbah plastik lebih 10 ton plastik setiap tahunnya diproduksi, dari jumlah tersebut, hampir seluruhnya diproduksi dari bahan minyak bumi. memproduksi plastik dalam jumlah tersebut dibutuhkan sekitar 12 juta barell minyak bumi per tahunnya. Jumlah ini mencapai $8 \%$ dari jumlah minyak bumi yang dihasilkan. Namun disamping masalah bahan baku yang berasal dari minyak bumi, ada masalah lain berkaitan penggunaan plastik, yaitu plastik merupakan bahan yang sulit di uraikan. Proses penguraian limbah plastik memerlukan waktu puluhan atau ratusan tahun untuk benar-benar terurai. Selain itu beberapa jenis plastik membutuhkan waktu 1000 tahun agar plastik dapat terurai dalam tanah terurai dengan sempurna. Proses ini membutuhkan waktu yang sangat lama. Saat terurai, partikel-partikel plastik akan mencemari tanah dan air tanah.

Sejak proses produksi hingga tahap pembuangan, limbah plastik memyebabkan emisi gas yang di lepaskan ke atmosfer seperti efek rumah kaca. Banyak hal yang harus dilakukan untuk mengatasi emisi gas Salah satunya dengan melakukan upaya kampanye untuk menghambat terjadinya pemanasan global. Sampah kantong plastik telah menjadi musuh serius bagi kelestarian lingkungan hidup. Sejumlah negara mulai mengurangi penggunaan kantong plastik diantaranya Filipina, Australia, Hongkong, Taiwan, Irlandia, Skotlandia, Prancis, Swedia, Finlandia, Denmark, Jerman, Swiss, dan lainlain.

Saat ini, salah satu cara untuk mengatasi limbah plastik yaitu dengan mengkonversi limbah plastik menjadi minyak dengan cara pirolisis. Menurut Sumarni dan Purwanti (2008:136), pirolisis merupakan proses peruraian suatu bahan pada suhu tinggi tanpa adanya udara atau dengan udara terbatas. Minyak limbah palastik yang digunakan sebagai alternatif mengurangi penggunaan bahan bakar yang umumnya digunakan juga harus disertai dengan mengetahui kadar emisi yang dihasilkan. Jangan sampai pemanfaatannya untuk mengurangi penggunaan bahan bakar lebih berdampak negatif dari pada kelangsungan hidup bagi manusia. Selama ini belum begitu diperhatikan tentang kadar emisi yang dihasilkan minyak limbah plastik tersebut. Kadar emisi yang melebihi ambang batas yang telah diijinkan akan sangat berbahaya. Menurut peraturan menteri lingkungan hidup tahun 2006 nomer 05, tentang ambang batas gas buang kendaraan bermotor.

\begin{tabular}{|l|l|l|l|l|}
\hline Katagori & Pembuatan & CO \% & HC ppm & Metode \\
\hline Sepeda motor 2 langkah & $<2010$ & 4,5 & 12000 & id \\
\hline Sepeda motor 4 langkah & $<2010$ & 5,5 & 2400 & Id \\
\hline
\end{tabular}

Sumber: Menteri linkungan hidup nomor 5 (2006)

Emisi gas buang yang berbahaya yang dihasilkan dari proses pembakaran antara lain gas hidrokarbon (HC) dan gas Karbonmonoksida (CO). Selain berbahaya bagi kesehatan manusia, peningkatan volume kendaraan serta meningkatnya polusi udara juga akan bedampak pada kondisi alam atau pemanasan global.

Rumusan masalah dalam penelitian ini bagaimana pengaruh variasi komposisi campuran bahan bakar dengan minyak plastik low density polyethyline (LDPE) terhadap emisi gas buang.

Adapun batasan masalah dalam penelitian ini, yaitu:

1. Limbah plastik yang akan di gunakan adalah plastik Low densiti polyethyline

2. Pengujian emisi di batasi pada $\mathrm{HC}$ dan $\mathrm{CO}$.

3. Sepeda yang di gunakan adalah supra Fit tahun 2005.

4. Campuran bahan bakar yang digunakan $A_{0}$ (premium murni), $A_{10}$ (premium $90 \%$ ). $A_{15}$ (premium $85 \%$ ), $B_{0}$ (pertalite murni), $B_{10}$ (pertalite $90 \%), B_{15}$ (pertalite $85 \%$ ), $C_{0}$ (pertamax murni), $C_{10}$ (pertamax 90\%), dan $C_{15}$ (pertamax $85 \%)$.

5. Hanya membahas tentang emisi gas buang pada kendaraan supra fit tahun 2005.

6. Tidak menghitung Rpm pada saat uji.

Adapun tujuan dalam penelitian ini adalah untuk mengetahui pengaruh variasi komposisi campuran bahan bakar dengan minyak plastik low density polyethyline (LDPE) terhadap emisi gas buang.

\section{METODE PENELITIAN} Diagram Alir Penelitian 


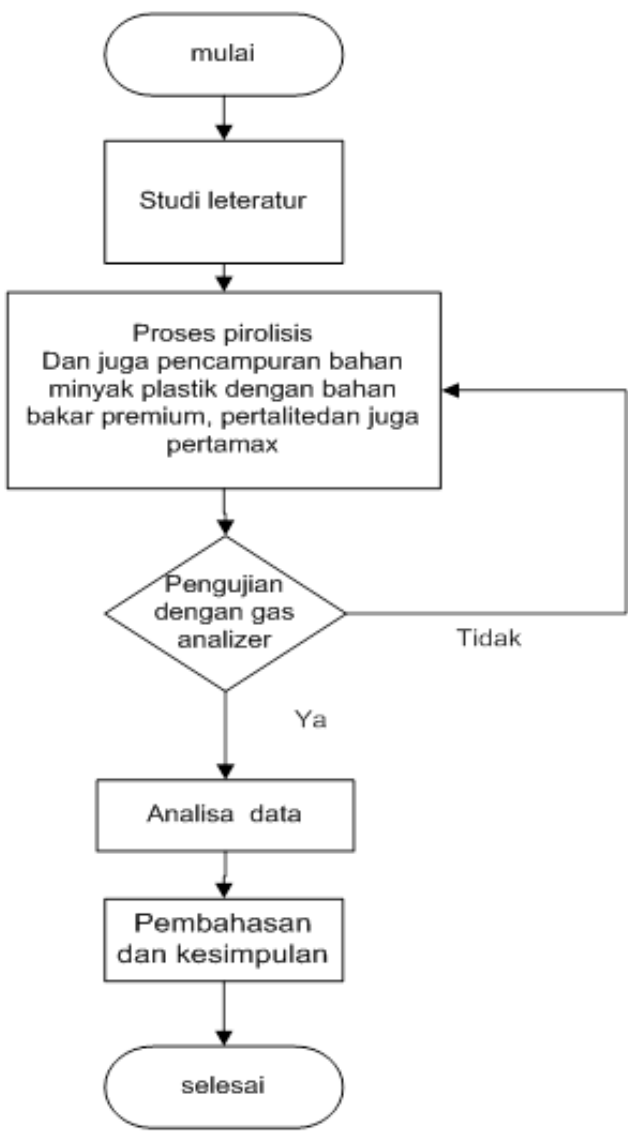

Gambar 1. Diagram Alir Penelitian

\section{Bahan dan Alat}

\section{Bahan}

Bahan yang di gunakan pada penelitian ini adalah:

1. Bahan pembuatan minyak plastik

- Plasik Low Densiti Polietilen (LDPE)

- Air.

2. Bahan uji emisi gas buang

1. sepeda motor Supra Fit tahun 2005.

2. $A_{0}$ ( premium murni ).

3. $A_{10}$ ( premium $90 \%$ dan $10 \%$ minyak plastik).

4. $A_{15}$ ( premium $85 \%$ dan $15 \%$ minyak plastik).

5. $B_{0}$ ( pertalite murni).

6. $B_{10}$ ( pertalite $90 \%$ dan $10 \%$ minyak plastik).

7. $B_{15}$ ( pertalite $85 \%$ dan $15 \%$ minyak plastik).

8. $C_{0}$ (pertamax murni).

9. $C_{10}$ (pertamax $90 \%$ dan $10 \%$ minyak plastik).

10. $C_{15}$ (pertamax $85 \%$ dan $15 \%$ minyak plastik).

Alat

Alat-alat yang di gunakan pada penelitian ini adalah sebagai berikut a. Alat pembuatan minyak plastik

- Guntiing digunakan sebagai pemotong bahan agar menjadi bagian - bagian yang kecil.

- Timbangan d.igunakan untuk menghitung banysk bahan yang digunakan.

- Kompor digunakan sebagai pemanas.

- Gas ELPIJI sebagai sumber bahan bakar.

- Gelas sebagai penampung hasil pirolisis.

- Kondensor sebagai pendingin.

- Tabung reaktor digunakan sebagai wadah bahan yang akan di proses.

b. Alat uji emisi gas buang

- Autocheck gas analizer, alat yang digunakan untuk menguji kandungan emisi gas buang pada kendaraan.

- Gelas ukur untuk mengukur banyaknya campuran.

- Tangki yang telah di modifikasi sebagai tempat bahan bakar yang akan di uji.

- Gelas ukur untuk mengukur campuran bahan bakar dan minyak plastik.

\section{Langkah - Langkah Pengambilan Penelitian}

Tahapan-tahapan dalam pembuata plastik menjadi bahan bakar sebagai berikut :

1. Proses Pemilihan Plastik LDPE

Proses pemilihan plastik LDPE sesuai dengan sifat fisik dan nomer plastik (LDPE) yaitu nomor 4 .

2. Proses Pencucian

Pada proses ini semua bahan plastik LDPE yang sudah dikumpulkan selanjutnya di bersihkan dengan air agar plastik LDPE menjadi bersih kemudian dikeringkan di bawah sinar matahari.

3. Proses Pemotongan

Proses pemotong ini di lakukan agar mempermudah reaksi pelelehan. Reaksi yang terjadi pada tabung reaktor.

\section{Proses penimbangan}

Plastik LDPE yang sudah bersih kemudian di timbang sekitar $3 \mathrm{~kg}$.

5. Proses Pirolisis

Pada proses ini plastik LDPE di panaskan pada suhu 400C di masukkan pada tabung reaktor,kemuadian di panaskan hingga mencapai fase cair dalam bentuk minyak. Metode pirolisis ini memerlukan waktu 1 jam dan 'hasil akhir berupa minyak LDPE.

Prepasasi uji emisi gas buang pada bahan bakar minyk LDPE yang di variasi dengan bahan bakar (premium, pertalite dan pertamax) langkah - langkah preparasi tersebut adalah 


\section{a) Preparasi Bahan Bakar}

Minyak plastik LDPE yang sudah diperoleh kemudian dicampurkan pada bahan bakar premium, pertalite dan pertamax, variasi dengan komposisi bahan bakar sebagai berikut : $A_{0}$ ( premium murni ), $A_{10}$ ( premium $90 \%$ dan $10 \%$ minyak plastik), $A_{15}$ ( premium $85 \%$ dan $15 \%$ minyak plastik), $B_{0}$ ( pertalite murni), $B_{10}$ ( pertalite $90 \%$ dan $10 \%$ minyak plastik), $B_{15}$ ( pertalite $85 \%$ dan $15 \%$ minyak plastik), $C_{0}$ (pertamax murni), $C_{10}$ (pertamax $90 \%$ dan $10 \%$ minyak plastik), $C_{15}$ (pertamax $85 \%$ dan $15 \%$ minyak plastik).

b) Tahap pengunjian emisi gas buang $\mathrm{CO}$ dan $\mathrm{CH}$

1. Memasang tangki yang telah di modifikasi pada kendaraan.

2. Memasang Gas Analyzer pada kendaraan.

3. Menyalakan mesin.

4. Mencatat data yang di peroleh.

5. Matikan mesin.

6. Menguras habis bahan bakar yang ada di karburator.

7. Pengujian di lakukan kembali mulai pada tahap 1-6 pada variasi komposisi bahan bakar selanjutnya.

c) Akhir pengujian

1. Matikan mesin

2. Lepas Gas Analyzer

3. Lepas tangki yang telah di modifikasi.

Lembar pengambilan data hasil hasil emisi Gas Buang CO dan HC

Tabel 1. Lembar Hasil pada Premium

\begin{tabular}{|c|c|c|c|}
\hline \multirow{2}{*}{$\begin{array}{c}\text { Kadar gas }- \\
\text { gas buang }\end{array}$} & Premium & \multicolumn{2}{|c|}{$\begin{array}{c}\text { Campuran dengan } \\
\text { minyak plastik }\end{array}$} \\
\cline { 2 - 4 } & $A_{0}$ & $A_{10}$ & $A_{15}$ \\
\hline $\mathrm{CO}$ & & & \\
\hline $\mathrm{HC}$ & & & \\
\hline
\end{tabular}

Tabel 2. Lembar Hasil pada Pertalite

\begin{tabular}{|c|c|c|c|}
\hline \multirow{2}{*}{$\begin{array}{c}\text { Kadar gas }- \\
\text { gas buang }\end{array}$} & Prertalite & \multicolumn{2}{|c|}{$\begin{array}{c}\text { Campuran dengan } \\
\text { minyak plastik }\end{array}$} \\
\cline { 2 - 4 } & $B_{0}$ & $B_{10}$ & $B_{15}$ \\
\hline $\mathrm{CO}$ & & & \\
\hline $\mathrm{HC}$ & & & \\
\hline
\end{tabular}

Tabel 3. Lembar Hasil pada Pertamax

\begin{tabular}{|c|c|c|c|}
\hline \multirow{2}{*}{$\begin{array}{c}\text { Kadar gas }- \\
\text { gas buang }\end{array}$} & Pertamax & \multicolumn{2}{|c|}{$\begin{array}{c}\text { Campuran dengan } \\
\text { minyak plastik }\end{array}$} \\
\cline { 2 - 4 } & $C_{0}$ & $C_{10}$ & $C_{15}$ \\
\hline $\mathrm{CO}$ & & & \\
\hline $\mathrm{HC}$ & & & \\
\hline
\end{tabular}

\section{HASIL DAN PEMBAHASAN Hasil Penelitian}

Pada penelitian telah di lakukan perubahan fasa padat menjadi cair pada sampel plastik LDPE dengan cara metode pirolisis pada suhu $400^{\circ} \mathrm{C}$. bahan yang di proses sebanyak $3 \mathrm{~kg}$ mengahasilkan $800 \mathrm{ml}$ minyak plastik. Kemudian minyak plastik LDPE di variasi dengan bahan bakar ( premium,pertalite dan pertamax ) untuk di uji emisi dengan alat Gas Analyzer agar memperoleh gas buang yang sangat minim.

Setelah dilakukan penelitian dan pengujian emisi gas buang pada campuran LDPE dengan bahan bakar premium, pertalite dan pertamax, maka di peroleh data sebagai berikut.

Tabel 4. Data Hasil Penelitian

\begin{tabular}{|c|c|c|c|c|}
\hline \multirow{2}{*}{ No. } & \multicolumn{2}{|c|}{ Komposisi Campuran } & \multicolumn{2}{c|}{ Emisi Gas Buang } \\
\cline { 2 - 5 } & Bahan Bakar & LDPE & HC & CO \\
\hline 1. & Premium $100 \%$ & $0 \%$ & $\begin{array}{c}1488 \\
\mathrm{ppm}\end{array}$ & $5,85 \%$ \\
\hline 2. & Premium $90 \%$ & $10 \%$ & $\begin{array}{c}882 \\
\mathrm{ppm}\end{array}$ & $4,61 \%$ \\
\hline 3. & Premium $85 \%$ & $15 \%$ & $\begin{array}{c}787 \\
\mathrm{ppm}\end{array}$ & $4,55 \%$ \\
\hline 4. & Pertalite $100 \%$ & $0 \%$ & $\begin{array}{c}1234 \\
\mathrm{ppm}\end{array}$ & $5,64 \%$ \\
\hline 5. & Pertalite $90 \%$ & $10 \%$ & $\begin{array}{c}826 \\
\mathrm{ppm}\end{array}$ & $4,7 \%$ \\
\hline 6. & Pertalite $85 \%$ & $15 \%$ & $\begin{array}{c}319 \\
\mathrm{ppm}\end{array}$ & $2,6 \%$ \\
\hline 7. & Pertamax 100 & $0 \%$ & $\begin{array}{c}1060 \\
\mathrm{ppm}\end{array}$ & $5,19 \%$ \\
\hline 8. & Pertamax $90 \%$ & $10 \%$ & $\begin{array}{c}921 \\
\mathrm{ppm}\end{array}$ & $4,86 \%$ \\
\hline 9. & Pertamax $85 \%$ & $15 \%$ & $\begin{array}{c}662 \\
\mathrm{ppm}\end{array}$ & $4,26 \%$ \\
\hline 10. & $0 \%$ & $100 \%$ & $\begin{array}{c}283 \\
\mathrm{ppm}\end{array}$ & $0,17 \%$ \\
\hline
\end{tabular}

\section{Pembahasan}

Berdasarkan data pada tabel 4.1 dapat di lihat bahwa campuran minyak plastik LDPE dapat menurunkan emisi gas buang karbon monoksida (CO) dan hidrokarbon (HC) berikut ini perbandingan nilai gas buang yang di gambarkan dalam grafik.

\section{Variasi komposisi minyak plastik LDPE dengan bahan bakar premium}

Hasil uji emisi gas buang campuran premium dengan minyak plastik LDPE pada gambar 4.1 
menunjukan nilai emisi gas $\mathrm{HC}$ pada premium murni adalah 1488 ppm.sedangkan pada variasi dengan di campurnya bahan bakar premium $90 \%$ dengan bahan bakar plastik LDPE $10 \%$ turun hingga 606 ppm. Pada variasi premium $85 \%$ di campur dengan minyak plastik $15 \%$ turun hingga $701 \mathrm{ppm}$.

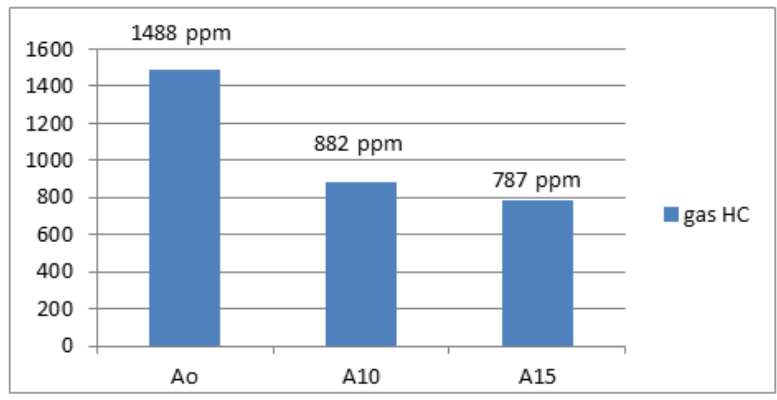

Gambar 2. Konsentrasi Gas Hidrokarbon (HC) pada

Uji Emis Gas Buang LDPE-Premium

Berdasarkan gambar di bawah ini menunjukan bahwa pada saat uji gas buang sampel premium murni memiliki kadar 5,85\%. Sedangkan pada variasi komposisisi premium $90 \%$ dengan bahan plastik LDPE $10 \%$ turun hingga $1,24 \%$. Sedangkan komposisi premium $85 \%$ di campur dengan plastik LDPE $15 \%$ turun hingga $1,3 \%$

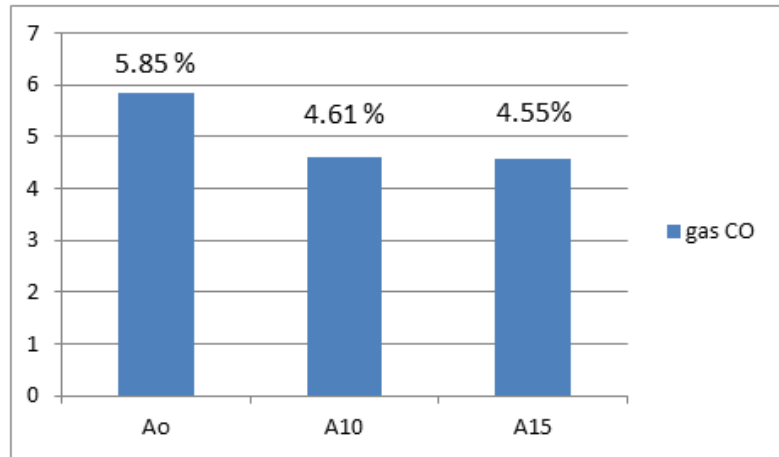

Gambar 3. Kadar Gas Karbon Monoksida (CO) pada Variasi Bahan Bakar Premium

Variasi komposisi minyak plastik LDPE dengan bahan bakar pertalite

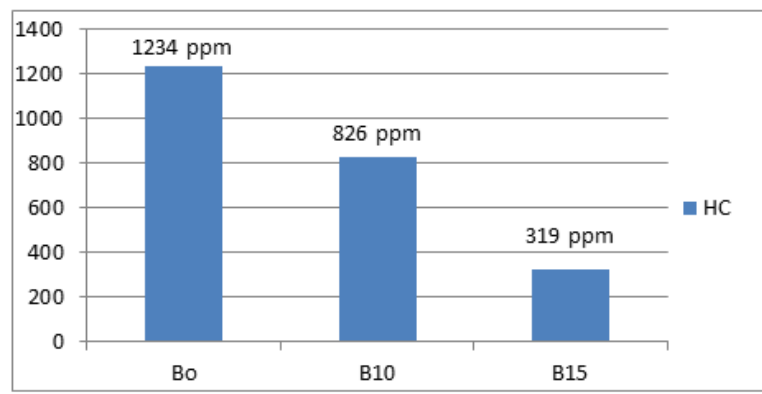

Gambar 4. Konsentrasi Gas Hidrokarbon (HC) pada

Uji Emis Gas Buang LDPE-Pertalite

Berdasarkan gambar di atas menunjukan bahwa pada saat uji emisi gas buang konsentrasi HC pada sampel variasi komposisi pertalite murni adalah 1234ppm.sedangkan pada variasi dengan di campurnya bahan bakar pertalite $90 \%$ dengan bahan bakar plastik LDPE $10 \%$ turun hingga 408 ppm. Padavariasi pertalite

$85 \%$ di campur dengan minyak plastik $15 \%$ turun hingga $915 \mathrm{ppm}$

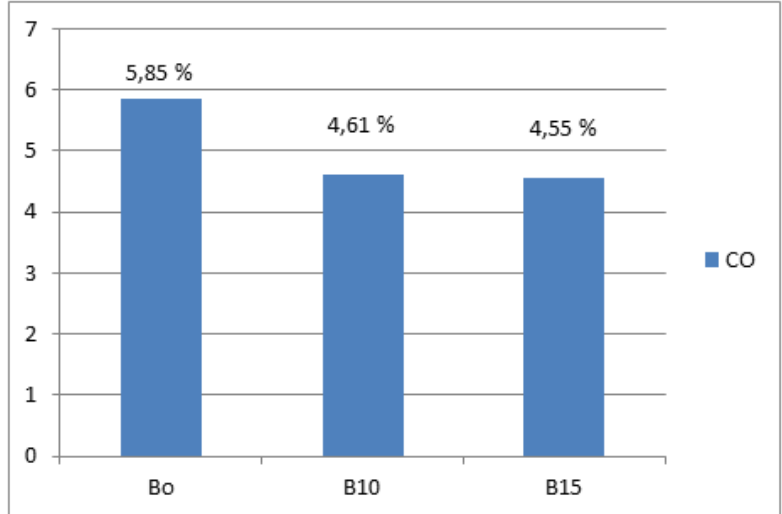

Gambar 5. Kadar Gas Karbon Monoksida (CO) pada Variasi Bahan Bakar Pertalite

Berdasarkan gambar di atas menunjukan bahwa pada saat uji gas buang sampel pertalite murni memiliki kadar 5,64 \%. Sedangkan pada variasi komposisisi pertalite $90 \%$ dengan bahan plastik LDPE $10 \%$ turun hingga $0,97 \%$. Sedangkan komposisi pertalite $85 \%$ di campur dengan plastik LDPE $15 \%$ turun hingga $3,04 \%$

Variasi komposisi minyak plastik LDPE dengan bahan bakar pertamax

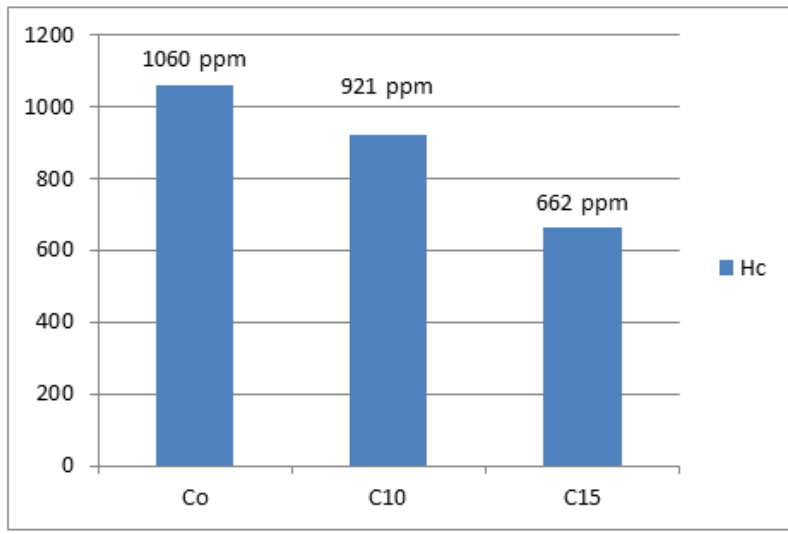

Gambar 6. Konsentrasi Gas Hidrokarbon (Hc) pada Uji Emis Gas Buang LDPE-Pertamax

Berdasarkan gambar di atas menunjukan bahwa pada saat uji emisi gas buang konsentrasi $\mathrm{HC}$ pada sampel variasi komposisi pertamax murni adalah 1060 ppm, sedangkan pada variasi dengan di campurnya bahan bakar pertamax $90 \%$ dengan bahan bakar plastik LDPE $10 \%$ turun hingga 139 
ppm. Pada variasi pertamax $85 \%$ di campur dengan minyak plastik $15 \%$ turun hingga 398 ppm.

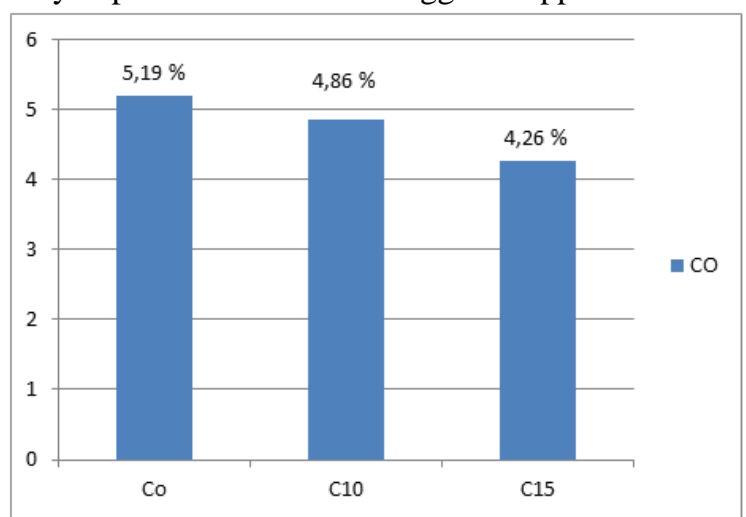

Gambar 7. Kadar Gas Karbon Monoksida (CO) pada Variasi Bahan Bakar Pertamax

Berdasarkan gambar 4.2 di atas menunjukan bahwa pada saat uji gas buang sampel pertamax murni memiliki kadar 5,19\%. Sedangkan pada variasi komposisisi pertamax $90 \%$ dengan bahan plastik LDPE $10 \%$ turun hingga $0,33 \%$. Sedangkan komposisi pertamax $85 \%$ di campur dengan plastik LDPE $15 \%$ turun hingga $0,93 \%$.

Berdasarkan hasil uji emisi gas buang kendaraan bermotor supra fit tahun 2005 yang telah di uji. Premium menunjukkan kadar gas buang emisi yang paling tinggi ini karna bahan bakar premium memiliki oktan 88. Sedangakan bahan bakar jenis pertalite memiliki oktan 90 lebih baik dari pada premium makan hasil yang di peroleh dari bahan bakar premium lebih baik. Untuk bahan bakar pertamax yang memiliki oktan sebesar 92 mendapatkan hasil paling bagus untuk kadar CO dan HC nya. Setelah di campurkan bahan bakar plastik LDPE bahan bakar premium mengalami penurunan baik gas $\mathrm{HC}$ maupun gas COnya ini berarti bahan bakar LDPE dapat terbakar di dalam ruang bakar secara sempurna sehingga gas yang di keluarkan bisa mengalami penurunan. Pertalite dan pertamax juga mengalami penurunan pada saat uji emisi berlang.

\section{PENUTUP}

\section{Kesimpulan}

Setelah dilakukan penelitian serta menganalisa hasil data pengujian dapat disimpulkan bahwa:

1. Minyak plastik dapat di campurkan kedalam bahan bakar premium, pretalite dan juga pertamax

2. Campuran minyak plastik LDPE mempengaruhi penurunan Emisi gas buang pada Hidrokarbon dan juga Karbon Monoksida
3. Plastik low density polietilen dapat menjadi bahan bakar alternatif

\section{Saran}

Penelitian ini hanya membahas tentang emisi gas buang pada kendaraan bermotor untuk lebih lanjut maksimal lagi perlu adanya pelitian selanjutnya tentang dampak bahan bakar minyak plastik terhadap performa dari kenerja mesin yang sedang memakai bahan bakar minyak plastik, mulai dari kecepatan dan juga dampak terhadap motor.

\section{DAFTAR PUSTAKA}

Aprian Ramadhan P. dan Munawar Ali pengolahan sampah plastik menjadi minyak menggunakan proses pirolisis jurnal vol. 4 no 44.

Kabib, Masruki. 2009. Pengaruh Pemakaian Campuran Premium Dengan Champhor Terhadap Performasi Dan Emisi Gas Buang Mesin Bensin Toyota Kijang Seri 4K. Jurnal Sains dan Teknologi. 2/2 1-17.

Peraturan Menteri Lingkungan Hidup Nomor 05 Tahun 2006. Tentang Ambang Batas Emisi Gas Buang Kendaraan Bermotor Lama.

PT. PERTAMINA. 2007a. Material Safety Data Sheet Pertamax. Jakarta. https://safetyrudi.files.word press.com/2010/02/03pertamax.pdf, Sabtu, 18 November 2017.

PT. PERTAMINA. 2007b. Material Safety Data Sheet Premium. Jakarta. https://safetyrudi.files.word press.com/2010/02/04premium.pdf, Sabtu, 18 November 2017.

Ramelan. 2011. Teori Motor Bensin dan Motor Diesel. Semarang : Universitas Negeri Semarang

Suyanto, Wardan. 1989. Teori Motor Bensin. Jakarta: P2LPT. 